\title{
On the Content and Contribution OF MCS IN BRITISH DRUM 'N' BASS
}

\author{
$\bullet$ FeAtUre Article \\ ALISTAIR Fraser \\ MAYNOOTH UNIVERSITY (IRELAND)
}

\begin{abstract}
Drum ' $n$ ' bass music has received some attention from academics but the contributions of MCs who perform onstage alongside DJs in live events and broadcasts needs further consideration. In response, and using MC lyrics, secondary interviews and Tweets, this article is a "critical celebration" of what MCs bring to British drum ' $n$ ' bass. The critique concerns the content of what MCs say, some of which I argue undermines the cultural and economic potential of the music. The celebration explores what MCs bring to drum ' $n$ ' bass, particularly practices that I suggest should be viewed as community services. I therefore argue that MCs are community workers, providing, leading, building and networking in ways that help generate solidarity, reciprocity, and alliances within and across an overlapping and diverse world of drum ' $n$ ' bass.
\end{abstract}

KEYWORDS: drum ' $n$ ' bass music, MCs, cooperation, electronic dance music

Alistair Fraser is Lecturer in Geography at Maynooth University, Ireland. His work cuts across political, economic and cultural geography, including research on the global food economy, land reform and agrarian change in South Africa, and British drum 'n' bass music.

Dancecult: Journal of Electronic Dance Music Culture 6(2): 42-60 ISSN 1947-5403 @2014 Dancecult http://dj.dancecult.net DOI 10.12801/1947-5403.2014.06.02.03 


\section{INTRODUCTION}

A key feature of British drum ' $n$ ' bass is the presence of MCs who perform alongside DJs in clubs and raves and on radio and Internet broadcasts. MCs usually rap, chant or "spit bars" on top of the music, sometimes with the aim of gently accompanying the music but also in many cases to hype up the crowd. As the author of one of the first books on drum ' $n$ ' bass, Brian Belle-Fortune, notes, "Essentially MCing involves someone speaking and/or singing over the DJ's records.... MCs fill the gap between DJs, the music and the audience. Interacting with the crowd, an accomplished MC turns a flat audience into a good one, a good audience into a hyper one" (1999: 144). MCs, then, are very much "the visible voices and faces of the Jungle Drum \& Bass scene" (Belle-Fortune 1999: 144). Thus, as in Jamaican dancehall (e.g. see Manuel and Marshall 2006) and live hip-hop, these lyrical contributions and voicings during live events are a central element of enjoying drum ' $n$ ' bass (Ferrigno 2008; Christodoulou 2009).

Like the music as a whole, which covers a broad range of styles, there is a reasonably large spectrum of MCs, from the more casual and relaxed styles of MCs such as Cleveland Watkiss, Justyce, Conrad or SP:MC, to the fast-paced, so-called "crowd hype MCs" such as Eksman, Funsta, IC3, Skibadee or the unique Shadow Demon Coalition MCs (Bassman, Trigga and Spyda). There are MCs who have been around since the first raves, such as MC: GQ, Navigator, and Det; but drum ' $n$ ' bass has also required that a newer generation emerge, as is perhaps best represented by MCs such as Harry Shotta or Messy. The scene for MCs is therefore quite vibrant as one of the leading MCs, Eksman, has noted recently: "Never in its history has Dnb had so many technical, talented mcs. It's beautiful to see" (MC Eksman 2013).

It is important to note here that MCs have always occupied a contentious position in drum ' $n$ ' bass. For many DJs, promoters and followers of the music, they are either not at all welcome or only to be tolerated in small doses: "Some punters and DJs love MCs [sic] participation. Others don't. Some revel in the unbroken lyrical, iambic, trochaic and free verse rhythms. Others just aren't in it" (Belle-Fortune 1999: 149). This tension leads some prominent MCs to claim that, "MCs by definition in this game are surplus to requirements" (Knowledge Magazine 2011a). It also means they are often excluded from many of the most important economic spaces in drum ' $n$ ' bass. For example, many radio shows, including the flagship (but late-night, off-peak) drum ' $n$ ' bass shows on BBC Radio 1 and Ministry of Sound Radio, usually run without MCs, perhaps due to pressure from record labels to let DJs profile tracks amidst a crowded and fragmented marketplace, or because the precise spontaneity of MC performances is overly-risqué. Some events promoters also tap into a sense among many ravers that MCs overdo it, performing inside events in a narcissistic way, claiming fame, demanding too much attention and ruining the music. MCs can undermine the collective feeling of raving, that sense that the crowd are trying to bounce off of the same vibe, which is then disrupted by an MC spitting bars, even bars about their own life, their importance, say, or their virility; in the process of celebrating their own significance 
and bolstering their cultural capital, MCs can alienate and upset: certainly any drum ' $n$ ' bass raver in Britain will be familiar with the tensions MCs create, not least with the figure of the raver dancing next to you who stops and shouts at you, 'I fuckin hate MCs'. Consequently, events such as Rupture in London-whose musical policy is very much at the experimental, less commercial end of the drum ' $n$ ' bass spectrum - have tried referring to MCs as 'hosts' in an attempt to place an emphasis on how the event will be about the music, rather than the surplus-to-requirements MC.

At the same time, in the same space of the club or rave, there are also many drum ' $n$ ' bass followers who enjoy what MCs do. There is clearly a market for their talents and interest in what they do. MCs are listed on flyers for drum 'n' bass events. They are booked by promoters to perform alongside specific DJs: Bassman with Grooverider, Skibadee with Hazard, MC DRS with Calibre, and so on. And whether spitting bars or performing call and response, there are usually always plenty of ravers buzzing off their contribution. Some ravers even sing along to what MCs say, knowing their most popular lyrics from tapes or $\mathrm{CDs}$ of live events or radio shows. Moreover, given the commercial success of grime MCs such as Dizzee Rascal and Wiley and their efforts in reorienting British music towards the MC (see Reynolds 2013: 638-40), there are certainly drum 'n' bass followers who turn up in part to hear what the star MCs of the scene have to say, even to compare what they can do on a more modest commercial scale with Dizzee or others. In short, drum 'n' bass MCs are definitely liked by many.

Regardless of perspective, however, MCs have played a fundamental part in the growth of drum 'n' bass music, retaining a strong position within the industry: walk into a drum 'n' bass tent at a rave or festival, or head along to a club in a small town or large city in Britain and the likelihood is that MCs will be present and performing alongside DJs. In this regard, of course, drum 'n' bass is quite different to most other EDM sub-genres that emerged from the early 1990s, although more recent sub-genres such as grime and dubstep have also emerged alongside an MC culture quite similar to or even more pronounced than drum ' $\mathrm{n}$ ' bass (see Hancox 2013; Reynolds 2013: 638-40).

Surprisingly, despite their prominent presence within drum ' $\mathrm{n}$ ' bass music, MCs have not received too much attention in the academic literature dealing with the music (e.g. see Morgan and Sidnell 2003; Ferrigno 2008; Fraser and Ettlinger 2008; Christodoulou 2009; Hall 2009; Christodoulou 2011; Fraser 2012). For instance, in a fascinating recent article in this journal, Christodoulou (2011) sidesteps any discussion of the role of MCs in the experience of bass fetishization in London's drum 'n' bass clubs. Hall (2009) also neglects any consideration of MCs in an otherwise insightful thesis examining the dancing body in drum ' $n$ ' bass club culture. Likewise, Fraser and Ettlinger's (2008) article on what they refer to as the "cultural economy" of British drum 'n' bass ignores the role MCs play in creating the spaces within and upon which the music has survived and thrived.

But MCs have not been entirely out of the picture. For example, Ferrigno (2008) draws on her research on drum 'n' bass in the U.S. to briefly note the importance of MCs within broader performance practices, such as the way MCs interact with DJs to produce rewinds 
or 'to talk about where they are from (e.g. 'representin' from the UK'), where they are performing, and what they and the DJ are doing for the audience (e.g. 'we're breakin' it down')" (2008: 86). And in his comprehensive review of the social dance space in drum ' $n$ ' bass culture, Christodoulou (2009) provides an excellent overview of the origins and meaning of MCs in drum ' $n$ ' bass (2009: 51-62). He demonstrates, for example, that MCs found a place in drum ' $\mathrm{n}$ ' bass by drawing on talents practiced in reggae sound systems popular among the Jamaican and broader West Indian community in London. As such, many of the most noticeable MC practices in drum ' $n$ ' bass can be traced to those origins, probably most especially the use of rewinds, which "involves the $\mathrm{MC}$ calling on the DJ to re-play a record from its opening bars in response to the exhortations of 'rewind' from the audience" (2009: 52). Moreover, the use of "call and response" interactions between MCs and the audience, which "involves a succession of two distinct phrases performed by different musicians, whereby the second is heard as a direct response to the first" (2009: 53), reflects the Black Atlantic diaspora (Gilroy 1993) of which many MCs are members. Such practices mean that drum ' $n$ ' bass audiences develop knowledge about what the response might be to specific calls, for example, by no means was it inevitable that everyone in an audience would know "Bo!" was the response to Stevie Hyper D's call of "Junglists are you ready?” (see also Morgan and Sidnell 2003).

Participation in drum ' $n$ ' bass culture therefore generates practices and activities that shape and define the vibe inside events. It follows from all this that MCs need to be seen as closely involved in "actively direct[ing] the social dance practices of the audience by coordinating their activities with the music being played by the DJ, of which the MC will be expected to have intimate knowledge as well as the ability to monitor the progress and mixing of records" (Christodoulou 2009: 60). This theme is also examined in depth in a fascinating essay by Morgan and Sidnell (2003), which draws on their analysis of MC performances in Canadian drum ' $\mathrm{n}$ ' bass events to demonstrate how MCs "collaborate in intricate ways with both the audience and the DJ" in a way that "provide[s] for the observable organization of the social setting" (2003: 271, 287). Thus, when an MC such as Det says "whistles massive blow, horns massive blow" and audience members do so, they show "that they have both attended to and understood the MC's talk and are therefore actively engaged in the ongoing course of action being constructed" (2003: 284).

\section{CONSIDERING THE ROLE OF MCS IN BRITISH DRUM 'N' BASS}

Although MCs have received some attention in the literature on drum ' $n$ ' bass, I argue more needs to be said. Specifically, I present what I refer to as a "critical celebration" of MCs in drum ' $n$ ' bass. Using a selection of MC lyrics, the article is "critical" of three features of what MCs say: sexist, misogynist lyrics; the extent to which MCs focus on party vibes rather than, say, political commentary on the society around them; and the use of a certain narrative about how their place in the drum ' $n$ ' bass culture reflects their talent and hard work. Following the critique, the latter part of the article then presents the "celebration". In part, I want to celebrate what MCs do because they deserve praise: for me, at least, 
and no doubt for many other followers of drum 'n' bass music, MCs have gone a long way towards giving the music its buzz, whether in the club or rave, over the airwaves, or while listening privately during a commute. This is not to say that MCs are always and everywhere a necessary part of the drum ' $n$ ' bass mix; clearly, as I have noted, there are many followers, not to mention DJs and promoters, who would rather do without them. Nevertheless, there is no denying that MCs have played a major part in producing the vibe, the hype of drum ' $n$ ' bass music, hence one reason for my celebration is to acknowledge the central role they play and have played over the last twenty years or so.

Further, when considering their role in British drum ' $n$ ' bass (as is my focus), respect is due to talented people from often quite harsh contexts who make a living and a career doing something they love, rather than muddling through often low-paid, casual or un-rewarding employment; that is, recognition is needed for people, like MC GQ, who can look back at what they have achieved and be thankful:

Coming from where I was coming from, wasn't really a great place, you know what I mean, when I was a youth still, do you understand what I mean? So, you know, the achievements of, from that, d'you know what I mean, with a lot of my friends banged up and whatever, to me doing what I'm doing, and me still kinda being on it, is like I gotta thank God for that, do you know what I mean? I always wake up and feel I'm really really grateful for this blessings that I have and for the opportunities to still fly and do my thing (Rinse FM 2012a).

That participation in forms of electronic dance music has enabled many such people to generate a living (and often a good living, with travel and the accumulation of experiences far beyond what most of their peers ever achieve) is already well known, especially with regards to DJs and music producers (e.g. see Fraser and Ettlinger 2008: 1650-1). But at least with respect to drum ' $n$ ' bass music, there is a risk that the achievements of DJs and producers overshadows those of MCs. This article aims to acknowledge the contribution MCs make.

There is also one final reason for celebrating drum ' $n$ ' bass MCs and it arises from my analysis of the role they play and the practices they perform inside and beyond the rave. Following Fraser (2012), I argue that drum 'n' bass, like other EDM genres, emerged and thrived via "relations of solidarity, reciprocity, generosity, caring, and empathy" (2012: 505); that is, there is an ethic of solidarity which helps produce a process of "accumulation by cooperation" by sharing knowledge, skills, and experiences. Drum 'n' bass is constituted in part by an arena in which cooperation can occur and a set of relationships that certainly values paid work and earning money, but it also entails relations that generate forms of reciprocity and alliances, from which much of the viability and vibrancy of the music and its cultural economy emerges.

Getting to grips with this feature of drum ' $n$ ' bass requires placing it in a wider context, one dominated by changes in British society, especially the emergence of neoliberal mentalities about economy and culture (e.g. see Harvey 2005: 55-63). As noted elsewhere 
(e.g. Collin 1997; Reynolds 2013), British rave culture emerged in the aftermath of Margaret Thatcher's push for deindustrialization and her attack on vestiges of working class unity, especially the trades unions. The emergent neoliberalizing society valued individualism and entrepreneurialism - values that fit and simultaneously clash with central aspects of rave culture. The fit is obvious: consider, for example, how a neoliberal mentality about how to live one's own life individually and entrepreneurially overlaps with the time spent dancing by one's self inside the rave, or the entrepreneurship that created new record labels, club nights, or broader promotion companies. There is an undeniable individualism and a strong spirit of entrepreneurialism in rave culture. We do find the 'bling', the signifiers of material success, even the sense that rave's heroes are in many ways Thatcher's children.

But at the same time, key values of rave and dance music cultures clash with post-industrial neoliberal society and its mentalities and sensibilities. Generating the buzz on the dancefloor is a communal, collective endeavour: an experience of sharing and feeding off of each other, not out-competing others, not out-doing them. Likewise, although entrepreneurship has been a central aspect in the successful endurance of rave and dance music cultures, among many of its entrepreneurs there remains a strong emphasis on staying independent - not selling up to a major company, say - not necessarily just chasing the money. And although the economic vitality of rave music cultures such as drum 'n' bass has been built in part by taking advantage of regulatory changes that reflect a neoliberalizing Britain, this is not to say that a raw, unfettered capitalism is its driving ethos. In short, it seems churlish to imagine that rave cultures would have somehow died in infancy were it not for the changes Thatcher pursued: parallels and overlaps between rave cultures and neoliberalizing society exist but so too do disconnects and tensions.

It follows from this that, in developing an understanding and then making something of the evident reciprocity and alliances we find in rave cultures such as drum ' $n$ ' bass, there might be some payoff in locating these practices relative to other examples occurring elsewhere within post-industrial, neoliberal, globalizing society. One particularly striking parallel to consider here is with work in the social sciences aiming to grasp contemporary forms of solidarity and cooperation (e.g. see Venkatesh 2002; Sennett 2003; GibsonGraham 2006; Sennett 2012). For example, even in the heartlands of neoliberal society - in fact, precisely in reaction to many of the worst excesses and outcomes of individualism and entrepreneurialism - there is immense social value attached to community work, to taking part and working together with others on projects of a diverse nature. In his call for attention to just such a pro-community spirit of cooperation, Richard Sennett (2012), argues that we need to understand the possibilities and limitations of working together; that is, how do practices of cooperation help communities take shape or contribute to their breaking up amidst harsh as well as relatively benign social and economic circumstances? Communities and a spirit of cooperation need to be understood but also celebrated, not least because they often run counter to today's hegemonic narrative of neoliberalism, which states that individualism trumps collective action or that entrepreneurship should outweigh solidarity. 
My aim is to examine how drum 'n' bass emerges from the continued effort to reproduce just such a spirit of cooperation. To be clear, in talking about drum ' $n$ ' bass in this way, I do not intend to suggest that its industry or scene is in fact a community; nor do I claim that drum ' $n$ ' bass is somehow devoid of internal divisions, politics, anger or resentment. But there does remain within the world of drum ' $n$ ' bass an identifiable loyalty to the music and to co-practitioners; and a clear belief that the music generates a particular type of buzz which demands respect and a future, as indeed the following tweet from MC Harry Shotta (@HaryShotta) demonstrates: "So much love for DNB \& all the Drums heads, you won't find another scene with such loyal supporters \& such energy in the raves" (Harry Shotta 2013). The point here: there is a drive among many drum ' $n$ ' bass practitioners, promoters and punters to generate a communitarian spirit; a feeling that such a community could emerge and in some cases does emerge, albeit temporarily within a rave or across a dispersed geographic setting during a live broadcast. Like other efforts to create the right feel on the dance floor, there is within drum ' $n$ ' bass a belief in the need to recreate the vibe generated in the early 1990s rave scene: that vibe of solidarity and sharing, of doing something original in a way that can cut across social differences and divisions.

As actors with a microphone who can verbalize emotions and sensibilities inside events, MCs have to be seen as key players in the production of this communitarian spirit. My aim is to demonstrate that MCs do a lot to translate and promote these sensibilities and beliefs about cooperation into relations and alliances that help move forward the music and those who produce and consume it. Specifically, I argue that MCs provide services, or more accurately that they perform 'community work' for audiences, promoters, and other artists.

The article uses a range of materials. One key source has been MC lyrics. Lyrics present the researcher of electronic dance music (EDM) with an unusual opportunity, given that the music has a strong instrumental influence. I argue that MC lyrics need to be seen as rich data that can be analyzed and interpreted. In part, my aim in this article is to look closely at the sorts of things that MCs say in their live performances. Although a lot of what they say is rather mundane (the sort of repetitive call and response discussed above), MCs also "spit bars" and produce meaningful rhymes that are highly interpretable. There is significant scope to interpret what they say, which this article seeks to attempt. And analysis of some contemporary MC lyrics highlights problematic and positive features. In addition to MC lyrics, I use materials from published interviews with drum ' $n$ ' bass MCs in magazines, blogs and radio shows; tweets written by drum ' $n$ ' bass MCs since mid-2011; and some of my own experiences as a follower of drum ' $n$ ' bass music since 1994. In terms of scope, my work has been focused on British drum 'n' bass MCs. I recognize at the outset a British focus offers only a very partial view of the general picture regarding MCs in drum 'n' bass music, since the music has grown geographically and its growth has generated new levels of diversity, much as is the case with global hip-hop culture; however I have not been able to conduct a broader analysis. 


\section{A Critique of Drum 'N' Bass MCs: Just Hot Chicks, Hotel Sex and MAINTAINING THE BUBBLE?}

As much as I might only like to celebrate what MCs do and what they have achieved, it is unquestionably the case that any such celebration must be balanced with a critique of some of the lyrics drum 'n' bass MCs "spit". Consider some lyrics from four sets of "bars", two from MC Funsta and two from Eksman, both of whom are popular and frequently-booked MCs in British drum 'n' bass:

Bars, it's all about bars,

Hot chicks ' $n$ fancy cars,

Do your own thing ' $n$ don't watch ours,

Uncontrollablez red like Mars.

(Kool London 2010)

Please, I only came here for the P's [pounds],

If I'm lucky, I might get some T I T's [breasts],

Roll up to the bar, a couple of JD's [Jack Daniels],

Only thing I wanna do is battle divvy MCs.

(Kool London 2010)

Acting like a gangster?

I'll act like a pimp.

I've got your girl's phone number, I might give her a link.

While you're working nine to five, I might take her for a drink.

Then I'll fuck her from behind, bent over the sink.

(Kool London 2011) ${ }^{1}$

Yo, she want some hotel sex,

Hotel sex, she want some hotel sex.

Hotel sex, she want some hotel sex.

In the shower in the bed, bent over the desk.

She says "aaaargh that feels amazing",

Ekser went stiff with the noise she was making.

Up down, up down, bed starts shaking,

Wall starts banging till my back starts aching.

(Kool London 2011)

Two points need to be made before proceeding to consider the broader significance of these lyrics. First, neither Funsta nor Eksman only spit bars such as these: both are versatile and talented MCs who have a wide repertoire of lyrics. Second, by no means is it possible to find all MCs in drum ' $n$ ' bass contributing lyrics such as these. Indeed, the counterpoint to what I aim to raise here is 
that drum ' $n$ ' bass does not have the same level of violently misogynist lyrics as can be found in some areas of U.S. hip-hop / rap (e.g. see Adams and Fuller 2006; Oware 2009).

Still, the objectifying message Funsta and Eksman send to women in drum 'n' bass audiences is clearly misogynist. They might not purposively contribute to the production of a space that is unwelcoming to women, but their lyrics achieve as much. These lyrics therefore need to be seen as partly generative of the highly masculinist tone of British drum ' $n$ ' bass. Despite efforts to attract women, including promotions that allow women free entry and attempts to book DJs who will play music at the less visceral end of the spectrum of drum 'n' bass, the British scene retains a "hard" feel.

The result: British drum ' $n$ ' bass has lost much of its female audience. As Hall (2009) notes, for example, the ratio of men to women in many events is often 80:20 and at best 60:40 (see also Hall 2009: 197-201). This gendered exclusionary tone to British drum ' $\mathrm{n}$ ' bass is particularly curious and problematic because it contradicts one of the music's more progressive elements: unlike many "elite" EDM events (e.g. see Measham and Hadfield 2009), entering a drum ' $n$ ' bass event will rarely, if ever, require conforming to any particular dress code: many drum ' $n$ ' bass practitioners take pride in the fact that the music broke down barriers, particularly racial and class differences within Britain (as I discuss below). Against this backdrop, it has to be seen as significant that two of the leading MCs in contemporary British drum ' $n$ ' bass have built their careers whilst using misogynist and exclusionary language. It also suggests that one key task of a drum ' $n$ ' bass $\mathrm{MC}$ is to parade their masculinity by chatting with a bunch of other guys; to show off and have a laugh in a way they think is fine, that is, by teasing each other, boasting about their supposed sexual prowess. It reflects their insensitivity to the diverse audiences to which they seek to appeal; and in this sense at least they undermine the potential for the sort of drum 'n' bass DJ they tend to perform alongside to truly reach beyond a parochial British male audience. Not surprisingly, lyrics by leading MCs such as Funsta have led some commentators within the industry to publicly call for an end, as the following tweet from drum 'n' bass journalist Joanna Ronson and subsequent (sarcastic) re-tweet by MC Funsta demonstrates: ““@JoannaRonson: @FunstaMC remember our little chat in Brizzle? no bars about fanny [vaginas] please. :P'> ooooh :(".

A second line of critique regarding British drum ' $n$ ' bass MCs is their tendency, if not to entirely eschew politics, then at least to avoid making the sorts of commentaries on contemporary society that their time holding the microphone affords them. There are some exceptions, of course. For example, perhaps one of the most significant lyrics here is MC Det's "Black, black, white, white, come together we unite", which evocatively speaks to some of the progressive racial politics within drum 'n' bass, which led MC 2Shy (@2SHYMC) to reflect in public, using the popular \#junglememories hashtag: "\#junglememories A scene that broke down all barriers regarding races, colours and creeds purely for the love of the music. Hardcore jungle d\&b" (2SHYMC 2011; also see Fraser 2012). In addition, in one of the few albums by drum ' $n$ ' bass MCs, I don't usually like MCs but... by DRS, there are some sharp political commentaries on contemporary Britain, not the least of which is his 
track Blackhearted, which takes aim at the treatment of children in British public housing schemes:

Blackhearted children from a home that's broken

Won't eat their greens but I'm sure they'll smoke 'em

Not even fully grown brain but they can't take the potent

But they can't take the pressure, the only way of coping

Today they're famous, yesterday nobody knows 'em

Nobody questions why they done it, why their youth was stolen

Growing in diseased streets, full with parasites and rodents

So why they travel in packs, hoods up, expressions frozen

Or why they cry themselves to sleep at night time

Lost in these dark estates searching for the right sign.

But where they live no shred of hope that you might find

With prostitute mothers selling bodies by the road side

Where drug addicts beat grandmothers for their pensions

Where the air's so dirty when you breathe it takes the stench in

Where alcoholics drink community spirits

You can see it in these kids' faces reaching their limits.

So politics-that is, the act of intervening and engaging with what is happening in society as a whole-does feature in drum ' $n$ ' bass. But the inescapable sense from the music is still that lyrics tend to focus on working with and alongside the music, rather than commenting on the society outside the club or rave. This sentiment is perfectly captured in an interview with MC Messy:

I'm fully aware of my job on stage, and think about a set in terms of its composition. I should simply be another layer to the tune, which is already massively layered and complicated. What I do should nestle nicely inside the music, with the aim of enhancing its impact.... I know the show isn't about me, and that I'm there to bridge the gap by interacting with the crowd, and maintaining the bubble. (Knowledge Magazine 2011b; my emphasis).

The conclusion: an ideal-typical drum ' $n$ ' bass MC should steer clear of speaking about society at-large and opt instead to "maintain the bubble". As Funsta has noted:

... as a voice and a focus point in the parties and on the airwaves, you have to send a positive message. Not only because it is the right thing to do, people come out to have a good time not to be reminded of the struggles they have to deal with all week! (Knowledge Magazine 2011a)

Perhaps this is fine; like EDM as a whole, drum 'n' bass is hedonistic and seeks to capitalize on the desire from punters to get away from it all for a few hours (Reynolds 2013). Maybe the best approach for a drum 'n' bass MC is just to downplay politics. Maybe the drum 'n' 
bass MC should avoid using their opportunity on the microphone to comment critically on the society in which they live, mirroring the prevalence of 'slackness' in Jamaican dancehall reggae, from which many drum ' $n$ ' bass MCs took inspiration (see excellent discussion on this issue in various parts of Christodoulou 2009). But what a shame. What a shame that not enough of these important and public practitioners of the music offer the sort of commentary on contemporary society that adds a rawness and an edge to the output of many of their peers in hip-hop (e.g. see Lamont Hill 2010). Deemon Rocka, one half of the Ragga Twins, has claimed that drum ' $n$ ' bass MCs need to blend "consciousness and party vibes" (Gale 2013): the evidence seems to suggest that the latter spirit is more important than the former.

A final line of critique of drum ' $n$ ' bass MCs is far less straightforward. To get there, some context is necessary. At issue is the economic and cultural history of drum ' $n$ ' bass. As noted elsewhere (e.g. Fraser and Ettlinger 2008; Christodoulou 2009), drum ' $n$ ' bass had humble origins in working and middle class areas of Britain from which DJs and producers made the music, often using rudimentary equipment, and worked with promoters to make events that took place beyond the more elite or at least mainstream night time economy. That drum ' $n$ ' bass has flourished so successfully over the last twenty years has been celebrated by many of its leading practitioners, many of whom would never have expected to lead such interesting and well-travelled lives if not for the music (see Belle-Fortune 1999; Fraser and Ettlinger 2008: 1650-1). There is, then, a "success narrative" within drum 'n' bass which goes like this: talent, when combined with hard work and entrepreneurialism, can deliver material change for working and middle class people, even amidst a harsh capitalist economy. This is a narrative that values persistence, professionalism, and a drive to succeed, rather than pursuing shortcuts via crime, for example. MCs seem to be key audible proponents of this view and some use their time on stage to advance it. Consider some lyrics from Funsta:

Do what you like and do what you wanna,

Don't grow up to be a suicide bomber,

You don't want FBI to be on ya,

Killin' innocent people gets you nowhere.

You want the eighth or the chains or the Hummers?

How you gonna get that?

Are you gonna get a Gat [Gatling, a type of gun]?

Go to university and get your brain fat.

That goes out to all, even if your face black.

Yeah I say that,

Put the A.K. back,

Wanna kill another jigga 'coz he's got more figures?

Try be the bigger man and get your own dinners!

(Funsta 2010) 
This rhyme is partly a commentary on the possibility that radicalized young people might turn to suicide bombing, as occurred in London in July 2005. But Funsta goes further by noting some of the other options facing young people in contemporary Britain: theft, guns, or suicide, but then also using talent, skill, education. Funsta speaks to the fact that many young people in Britain (and many of those in the audiences of clubs or raves in which he performs) will turn to criminal activities for an income given the limited possibilities of finding well-paid employment in the mainstream economy. His message is not to take this route: if you want to get "the eighth [of an ounce of cocaine or marijuana] or the [gold] chains or the Hummers [Humvee, an automobile produced by AM General]", do not get a gun but rather "Go to university and get your brain fat".

I argue the lyrics also have to be seen in the context of the success narrative within drum ' $n$ ' bass as a whole. The call on audiences is to do as the leading practitioners of drum 'n' bass have done: doing the mileage, being professional, putting in the graft; not to rest on their laurels but to get up and get out there, very much in the way Margaret Thatcher's Conservative governments called upon the British working class to forget waiting for unions or the state to help them and instead become entrepreneurial and forge their own paths towards material enrichment. Rather than taking short cuts, rather than getting a Gat, the message here is to work hard while in education, say, or via developing an entrepreneurial spirit. That numerous MCs from related genres such as grime have gone on to achieve considerable commercial success only reinforces this sense, even though the hard work that many people in their audiences undertake in the mainstream economy will rarely bring such rewards. This final issue is the crux of the matter: maybe the leading practitioners of drum 'n' bass have achieved their success through hard work and entrepreneurialism; and maybe that route is open to all. Yet, for every leading light who can talk about their path to success, there are countless others who never managed to overcome the various and multiple constraints and obstacles that confront those who want to avoid the mainstream economy or let their latent shine. "Do[ing] what you like and do[ing] what you wanna" is not quite as simple as it sounds. Moreover, the quite individualistic view within the success narrative, one that champions personal development, would have few opportunities to be heard if MCs did not also perform a range of other critical roles within drum ' $n$ ' bass; roles that contribute to the overall success of the music and which in turn enable MCs to reflect on their individual success. Any critique of this aspect of drum ' $n$ ' bass MCs must therefore be juxtaposed with a degree of celebration of the cooperative spirit pervasive within the "scene".

\section{A Celebration: MC Practices Inside and Beyond the Rave}

MCs stand (literally, on stage, holding their microphones) at the centre of a drum ' $n$ ' bass scene in which actors work to generate a communitarian spirit. Their most important actions are certainly the words they speak or shout or sing, but as scholars we also need to consider a range of other practices; that is, attention needs to be paid to what MCs do inside and beyond the rave. 


\section{COMMUNITY WORK INSIDE THE RAVE}

One among many ways that drum ' $n$ ' bass connects with my raving life is the way ravers can shape how events unfold. Of course, like any dance music event, if no-one gets up and moves then the vibe is never going to be up to much. But in drum ' $n$ ' bass there is one practice that has gone a long way to make events just that little bit more interactive and participatory: the rewind. Drum ' $n$ ' bass is not the only form of dance music in which these can be found, but it is certainly the case that the practice has played a major part in its success. As Morgan and Sidnell (2003) and Christodoulou (2009) noted, rewinds happens when a DJ drops a particularly good track, perhaps one that ravers have never heard before, or when a 'classic' is played (such as Konflict's Messiah or Alex Reece's Pulp Fiction).

One indicator that a rewind will occur is the crowd reaction: shouts from the crowd of "bo-bo-bo" or waving hands in the air. The MC is a crucial mediator in these situations; although rewinds can happen even without them, when present a key task for the MC is certainly to interact with the crowd and use the microphone to call to the DJ for a rewind, often to the annoyance of the DJ who might already have begun mixing in the next track (hence this can be one source of tension between DJs and MCs). There is, therefore, a fair bit of interaction between the MC, sometimes the DJ, and the raving crowd inside drum ' $n$ ' bass events, precisely because ravers know there is the possibility that a meaningful track can be pulled up and played again. For this reason, MCs are not just welcomed by many drum 'n' bass followers, but for plenty they are absolutely central to the vibe, to the very buzz they are seeking; hence, drum 'n' bass in a club or rave without an MC can feel under-populated, empty, even quiet. When they are doing their job effectively, MCs hype up the audience and make events exciting, more enjoyable, even unforgettable. Thus, according to MC Dynamite, who rose to fame in drum ' $n$ ' bass via magical performances alongside Roni Size in the mid-1990s: "Live performances are all about getting the crowd involved, making them feel like every tune is their favourite, even if they haven't heard it before" (Knowledge Magazine 2011c).

Stepping back and contemplating the significance of these roles, it is important to view MCs not just as collaborators inside the rave but also as providers of a service. And not just these services. For example, MCs might pass on information about tracks played by DJs, which is especially welcomed by those so-called "trainspotters" who desperately want to know which producer made which track. Then there are the requests for security or the promoter to come to the DJ booth; for the driver of a car with a certain license plate to go outside and check their vehicle; and of course for the sound engineer to turn up the volume. MCs also pass on various messages to their audiences and to other artists and industry insiders, which might take the form of a "shout out", "big up", or a "hold tight" to this or that MC, DJ, producer, promoter, or whoever. Finally, there are also various "shouts" to people in the audience in live events (or to listeners to web or radio shows who might send in SMS text messages or emails). These sorts of voicings are far from mundane. They signify who is important, who deserves to be mentioned; and they might be used to help cement otherwise weak ties between different "crews" or groups of drum 'n' bass practitioners. 
I suggest that all of these services are forms of community work akin to what Sennett (2012) argues is needed to make cooperation viable. In their interactions with the crowd to get rewinds or through shout outs or demands on sound engineers, MCs "practise commitment" (2012:247-73) to drum ' $n$ ' bass by passing on and helping to build knowledge about its world in a way that makes attending an event seem important, worthwhile, valuable. Given the origins of the music in the early 1990s rave scene in Britain and especially the ground-up and communitarian spirit that existed then, these forms of community work retain a value in drum ' $n$ ' bass: there remains a real sense that the music and the culture and economy around it should be cooperative, collaborative, shared, as well as independent and strong. Although they appear to be performing a seemingly mundane set of services inside the rave, MCs need to be viewed as crucial interlocutors in the ongoing effort to renew solidarities and build a set of collaborative relations that help make it possible for drum ' $n$ ' bass to survive and expand.

\section{BEYOND THE RAVE: LEADING, BUILDING AND NETWORKING}

What they do inside the rave is important; but MCs perform a range of other practices that also need to be seen as community work. There are two sets of issues to consider here. The first is what I refer to as their practices of "leading and building". One key way to see this is to note how active some prominent MCs have been in promoting their own events and re-shaping the scene as they do so. MC Eksman, for example, has been successfully running his own Overload events since 2009. He discussed how this emerged in a recent interview:

Alright, so basically there was a guy from Bristol who used to run a night called Overload and I used to perform down there at all his gigs...and he was selling his brand, he was like he's had enough, it's not working for him; and I saw what he'd built up and I thought do you know what with what I could bring to the table I could make this work..." (Rinse FM 2012b).

His efforts have paid off: Overload events continue and have become a mainstay on the crowded London drum 'n' bass calendar.

Meanwhile, another London-based MC, Shabba D, has had success with his Sticky events, a selling point of which is that women enter free of charge (at least, before $11 \mathrm{pm}$ ). Part of his thinking was that not enough women were attending drum ' $n$ ' bass events (as I noted earlier in the article); as such, his efforts have been aimed at trying to re-make the terrain in which drum ' $n$ ' bass is played:

... I MC at different venues all over the country and world and I just don't think there's enough girls in drum 'n' bass.... I think there's less trouble when there's more girls in the place, you know, why you gonna fight with a man when there's ten sexy girls in front of ya dancing?... And we started off really small and it's just got big, man. 
... And not maximum promotion, as well, we just done things our way and maybe a couple of times last minute, but I think Scala has helped us as well, because that's a big venue and to the drum 'n' bass ravers, they don't get to use it all of the time, either, so that's been good for us.... And they've all been good, man.... So we do Girls Don't Pay and we got Sticky Presents Masters of Ceremony which is more based on the $\mathrm{MC}$, which is what I am, so for the up-and-coming man to come through as well, so it's a good thing, do you know what I mean? And yeah some of the parties: different crowds, different crowds, people come to the raves and say 'you know what Shabbs, that's a different crowd'" (Rinse FM 2011).

As Shabba notes, running events is not just about building and shaping the way drum ' $n$ ' bass is experienced; rather Shabba is showing leadership by trying to "bring in" up-andcoming talent, something Eksman has also discussed with respect to his events:

If you want the scene to move forward you've gotta bring in the new talent, you can't be greedy.... The longer the scene is, the longer everyone eats.... What makes me different to a lot of promoters is that I'm an artist, I know what it's like to come through (Rinse FM 2012b).

In taking on these tasks, both Eksman and Shabba are showing leadership, striving to build the scene, making a difference. They have not been satisfied with receiving bookings but have opted instead to shape the cultural economy of drum ' $n$ ' bass. And much of that work they have done for themselves, as Eksman noted:

Just 'cause I am who I am it doesn't mean I can't stand outside a rave and put in the work. Even the other night I was out putting up boards and stuff. At the end of the day if you want something you gotta put in the work and that's what I'm all about (Rinse FM 2012b).

If the first way to see MCs performing community work beyond the rave is their practices of leading and building, the second set of issues is about their work as "networkers". In part, this sort of work reflects the overlapping nature of drum 'n' bass, with various "crews", such as those associated with a particular record label or radio station, or even perhaps groups from a particular area. But these groups overlap, working and performing together in events or by remixing each other's music. As I have noted, one role that MCs have inside the rave is to give "shout outs" to individuals as well as members of these various crews. Outside the rave, too, MCs take on this role over the airwaves or on internet broadcasts. It follows from this that MCs should be viewed as key linkers, making connections, "bigging up" others, or spotting opportunities to emphasize the community vibe needed to make an event roll. As the following quote from MC Eksman demonstrates, by having a microphone and the time and space to speak to their audience, MCs have the opportunity to pass on thanks, recognition, big ups; that is, they have the opportunity to go beyond collaborating and leading by linking up the overlapping networks that constitute the drum ' $n$ ' bass: 
Hold tight the Kool crew, maximum boost going out every time. Hold tight all the DJs, all the MCs, all the producers, promoters, everybody involved in our scene in England abroad, everywhere, making it strong. Remember it's not about competing, it's about linking, making it bigger [...] Right we're signing out like this. Original. Logan-D, Eksman, Herbzie. Don't forget to catch us up here a bit more. That's right. Representing drum $n$ bass. Time to put the work in. And represent. To all the followers. Hold tight the Brockie. Hold tight the Ragga Twins. Hold tight the Shabba, Fatman [...] Hold tight the Skibba wherever ya dere, big up the Harry Shotta what's going on, fam? To all the massive representing drum \& bass jungle making moves, hold tight the Danny Friction. Hold tight the SP. Big. Out to the Biggie, hold tight Majika, hold tight Joe, that's how we roll. Out to the Lloyd, big up all the Innovation crew, hold tight Ollie. Hold tight the Phantasy. Hold tight the Clayton, hold tight all the Breakin Science massive, yeah? Hold tight the Definition Crew. To everybody making moves. (Kool London 2011; my emphasis)

In addition to these forms of collaboration, MCs have been, and are arguably becoming more important as providers of lyrics on tracks made by drum ' $n$ ' bass producers. Of course, inside the club or the rave MCs collaborate by adding a live lyrical layer to mostly instrumental music and this helps create the vibe on the dance floor; such practices of live collaboration multiply the power of the beats and knowing that MCs might add such lyrics frees up producers to make instrumental music. Drum ' $n$ ' bass MCs also conduct studio work, even if not as much as some MCs would like: for example, MC Eksman has discussed his regret at the limited amount of time producers have given MCs to make vocal tracks (Rinse FM 2012b). Unlike the outstanding commercial success of grime MCs, few of these collaborations have hit the charts, perhaps with the exception of DJ Marky, XRS and MC Stamina's $L K$.

I argue these practices make MCs key networkers in drum 'n' bass. They spend time in the studio with producers and work to create outputs that might have commercial potential, but more realistically and practically are aimed at busting up dance floors; that is, these forms of collaboration are not just about getting in the studio to make tunes that can make money, but are undertaken for the sake of the art, for the sake of doing something that will last, indeed for the sake of doing something that will contribute to the greater good. In a way, then, these collaborations are aimed at leaving a mark, which one drum 'n' bass pioneer, Doc Scott (@docscott31), has called on others to consider in a recent tweet: "When everything is said \& done. Did you leave a legacy? Did you make a mark? Were you even noticed? Or did you just make some money?" (Doc Scott 2012).

\section{CONCLUSION}

Like other forms of EDM, drum 'n' bass has its own feel, its own vibe. On the dance floor, it is very much about building up for the drop, letting it come down, riding the rolling bassline, enjoying the mixdown, waiting for the next drop, and bam: we're off again. Drum 
'n' bass has both a jump-up-and-down, as well as a roll-with-it, let-it-flow feel. MCs add to all this, at least in my view. They perform, act, work it; they move the audience, bring them along, take them away, even. They are important. Having people who take a microphone and "spit bars", as well as provide the sorts of community services I have explored above, has been an asset to drum 'n' bass. MCs have helped the "scene" survive and thrive. Thus, this group of lyrically-proficient and often highly talented MCs has been critical in creating

a vibrant, exciting and interconnected world of drum ' $n$ ' bass, thereby contributing to the creation of what Dowdy (2007) has referred to as its 'interactive spaces of collective identity' (Dowdy 2007). But as this article has also reviewed, MCs also undermine drum 'n' bass. In part because many of them are in (what Chang [2007: 335] has elsewhere referred to as) the "[f]ullest agitation of their becoming", some of their lyrics are misogynist and exclusionary. It follows that, inasmuch as I believe scholars of EDM need to celebrate the way MCs have built careers and lives, incomes and opportunities in ways that empower them, albeit in a fragile way, to accumulate wealth and experience via numerous forms of cooperation; such a celebration needs to be tempered by recognizing how they also undermine the sort of vibe and feel that I expect all of us love about EDM.

\section{NOTES}

1 Calling attention to Eksman's dig at the nine to five worker must be balanced by the following Tweet: “@Eksman_mc After this early morning rise, I salute all the 9-5 people... Makes me appreciate my job a million times more!” (MC Eksman 2012).

\section{REFERENCES}

Adams, Terri M. and Douglas B. Fuller. 2006. "The Words Have Changed but the Ideology Remains the Same-Misogynistic Lyrics in Rap Music." Journal of Black Studies, 36: 938-57. <http://dx.doi.org/10.1177/0021934704274072>.

Belle-Fortune, Brian. 1999. All Crew Muss Big Up: Journeys Through Jungle Drum \& Bass culture. Basildon, UK: Remix.

Chang, Jeff. 2007. Can't Stop Won't Stop: A History of the Hip-Hop Generation. London: Ebury. Christodoulou, Chris. 2009. "Renegade Hardware: Speed, Pleasure and Cultural Practice in Drum 'n' Bass Music." Ph.D. Dissertation (Centre for Media and Culture Research), London South Bank University.

- - 2011. "Rumble in the Jungle: City, Place and Uncanny Bass." Dancecult:Journal of Electronic Dance Music Culture, 3(1): 44-63. <http://dx.doi.org/10.12801/1947-5403.2011.03.01.03>. 
Collin, Matthew. 1997. Altered State: The Story of Ecstasy Culture and Acid House. London: Serpent's Tail.

Doc Scott. 2012. Twitter post, March 5, 12:35 p.m., < $\underline{\text { http://twitter.com/docscott31 >. }}$

Dowdy, Michael. 2007. "Live Hip Hop, Collective Agency, and 'Acting in Concert' (Hannah Arendt's notion)." Popular Music and Society, 30: 75-91. $<$ http://dx.doi.org/10.1080/03007760500503459>.

Ferrigno, Emily. 2008. “Technologies of Emotion: Creating and Performing Drum 'n' Bass.” Ph.D. Dissertation (Ethnomusicology), Wesleyan University.

Fraser. Alistair. 2012. "The Spaces, Politics, and Cultural Economies of Electronic Dance Music." Geography Compass, 6(8): 500-11. <http://dx.doi.org/10.1111/j.1749-8198.2012.00505.x >.

Fraser, Alistair and Nancy Ettlinger. 2008. "Fragile Empowerment: The Dynamic Cultural Economy of British Drum and Bass Music." Geoforum, 39: 1647-56. <http://dx.doi.org/10.1016/j.geoforum.2008.03.003>.

Gale, Matthew. 2013. The Junglist Soldier- The Life and Times of Stevie Hyper D.: < http://www. mixcloud.com/matthew-gale/the-junglist-soldier-the-life-and-times-of-stevie-hyper-d/> (accessed 28 August 2013).

Gibson-Graham, J.K. 2006. A Postcapitalist Politics. Minneapolis: University of Minnesota Press. Gilroy, Paul. 1993. The Black Atlantic: Modernity and Double Consciousness. London: Verso. Hall, Joanna Louise. 2009. "Heterocorporealities: Popular Dance and Cultural Hybridity in UK Drum 'n' Bass Club Culture." Ph.D. Dissertation (Dance, Film and Theatre), University of Surrey.

Hancox, Dan. 2013. Stand Up Tall: Dizzee Rascal and the Birth of Grime. Amazon Digital Services, e-book.

Harvey, David. 2005. A Brief History of Neoliberalism. Oxford: Oxford University Press.

Knowledge Magazine. 2011a. Funsta Interview. 8 March: <http://www.kmag.co.uk/editorial/ features/funsta-interview.html $>$ (accessed 28 August 2013).

- - - 2011b. Messy MC Interview. 4 March: < http://www.kmag.co.uk/editorial/features/ messy-mc-interview.html $>$ (accessed 28 August 2013).

———.2011c. Dynamite MC Interview. 8 March: <http://www.kmag.co.uk/editorial/features/ dynamite-mc-interview.html $>$ (accessed 28 August 2013).

Lamont Hill, Mark. 2010. "Critical Pedagogy Comes at Halftime”. In Born To Use Mics: Reading Nas's Illmatic, ed. Michael Eric Dyson and Sohail Daulatzai, 97-114. New York: Basic Civitas Books.

Manuel, Peter and Wayne Marshall. 2006. "The Riddim Method: Aesthetics, Practice, and Ownership in Jamaican Dancehall." Popular Music, 25: 447-70. <http://dx.doi.org/10.1017/S0261143006000997>

MC 2Shy 2011, Twitter post, December 9, 4:51 p.m., <http://twitter.com/2SHYMC $>$. MC Eksman. 2012. Twitter post, April 16, 8:31 a.m., <http://twitter.com/Eksman mc $>$. ——-.2013. Twitter post, January 8, 1:57 p.m., <http://twitter.com/Eksman_mc $>$.

MC Funsta. 2011. Twitter post, December 6, 4:30 p.m., <http://twitter.com/FunstaMC $>$. MC Harry Shotta. 2013, Twitter post, August 24, 1:02 a.m., < http://twitter.com/HarryShotta $>$. 
Measham, Fiona and Phil Hadfield. 2009. "Everything Starts With an 'E': Exclusion, Ethnicity and Elite Formation in Contemporary English Clubland." Adicciones, 21:363-86.

Morgan, Gerard and Jack Sidnell. 2003. "'Trying to Break It Down': MCs' Talk and Social Setting in Drum \& Bass Performance”. In Global Pop, Local Language, ed. Harris M. Berger and Michael Thomas Carroll, 269-90. Jackson, UK: University Press of Mississippi.

Oware Matthew. 2009. “A 'Man's Woman'? Contradictory Messages in the Songs of Female Rappers, 1992-2000." Journal of Black Studies, 39: 786-802. < http://dx.doi.org/10.1177/0021934707302454 >.

Reynolds, Simon. 2013. Energy Flash: A Journey Through Rave Music and Dance Culture. London: Faber and Faber.

Rinse FM. 2011. Uncle Dugs with special guest MC Shabba D. 11 No 2011: <http://www.mixcloud.com/Dizzyuk/rcff-uncle-dugs-rinse-fm-special-guest-mcshabba-d-111111/> (accessed 28 August 2013).

_-_. 2012a. Uncle Dugs with special guest MC GQ. 25 May 2012: < http://www.mixcloud.com/Dizzyuk/rcff-uncle-dugs-rinse-fm-special-guest-mc-gq-25512/> (accessed 28 August 2013).

- - 2012b. Uncle Dugs with special guest MC Eksman. 27 July 2012: <http://www.mixcloud.com/Dizzyuk/rcff-uncle-dugs-rinse-fm-special-guest-mceksman-27712/> (accessed 28 August 2013).

Sennett, Richard. 2012. Respect in an Age of Inequality. New York: Norton.

- _ . 2012. Together: The Rituals, Pleasures, and Politics of Cooperation. London: Yale University Press.

Venkatesh, Sudhir. 2002. The Rise and Fall of a Modern Ghetto. Cambridge, Mass.: Harvard University Press.

\section{DISCOGRAPHY}

Alex Reece. 1995. Pulp Fiction. Metalheadz (12-inch): METH 011. <http://www.discogs.com/Alex-Reece-Pulp-Fiction-Chill-Pill/release/2779665>.

DJ Marky and XRS. 2002. LK 'Carolina Carol Bela'. V Recordings (12-inch): V035. <http://www.discogs.com/DJ-Marky-XRS-Featuring-Stamina-MC-LK-Carolina-Carol-Bela/ release $/ 3124941>$.

Konflict. 2005. Messiah. Renegade Hardware (12-inch): RH65. < http://www.discogs.com/Konflict-Messiah-Beckoning/release/391800>.

Kool London. 2010. DJ Ruffstuff with MC Funsta.

Digital recording no longer available online.

_-_. 2011. DJ Logan D with MC Eksman and MC Herbzie.

Digital recording no longer available online.

MC DRS. 2012. I Don't Usually Like MCs But... Soul:R (14× File, Album, MP3): SOULR057. <http://www.discogs.com/DRS-I-Dont-Usually-Like-MCs-But/release/3830179>. 